Revista Brasileira de Agricultura Irrigada v.10, nº.2, p. 486 - 495, 2016

ISSN 1982-7679 (On-line)

Fortaleza, CE, INOVAGRI - http://www.inovagri.org.br

DOI: $10.7127 /$ rbai.v10n200355

Protocolo 355.16 - 29/10/2015 Aprovado em 04/03/2016

\title{
CRESCIMENTO INICIAL E TOLERÂNCIA DE CULTIVARES DE PEPINO SOB ESTRESSE SALINO
}

José Ricardo Tavares de Albuquerque ${ }^{1}$, Francisco Vanies Da Silva Sá ${ }^{2 *}$, Fernanda Andrade de

Oliveira $^{3}$, Emanoela Pereira De Paiva ${ }^{1}$, Erbia Bressia Gonçalves Araújo ${ }^{3}$, Lauter Silva Souto ${ }^{3}$

\section{RESUMO}

O pepino é uma hortaliça de grande importância econômica e alimentar, devido a sua apreciação como componente de saladas. No entanto, o seu cultivo no semiárido apresenta risco, devido aos problemas de salinidade, sendo necessária a identificação de cultivares tolerantes, que se desenvolvam melhor em ambientes com problemas de salinidade. Com isso, Objetivou-se avaliar a emergência, o crescimento e a tolerância de cultivares de pepino ao estresse salino. $O$ experimento foi desenvolvido em ambiente protegido (casa de vegetação) localizado no município de Pombal, Paraíba, PB. O estudo foi arranjado em esquema fatorial 2 x 5 um delineamento experimental inteiramente casualizado, constituído de duas cultivares de pepino (C1 - Aopdai e C2- Wisconsin SEM-58) e cinco níveis de salinidade da água de irrigação $\left(0,6\right.$ (controle); 1,2; 1,8, 2,4 e 3,0 dS m$\left.{ }^{-1}\right)$ com quatro repetições e dez plantas por parcela. As plantas de pepino foram conduzidas por 20 dias, nos quais se avaliou a emergências de plântulas, $o$ crescimento inicial, o acúmulo de biomassa e o índice de tolerâncias das cultivares com relação ao rendimento de biomassa. A salinidade da água de irrigação afeta a emergência, o crescimento e o acúmulo de massa seca das plantas de pepino. A cultivar Aopdai apresenta os maiores índices de emergência, o crescimento e o acúmulo de massa seca em relação a cultivar Wisconsin SEM-58. A cultura do pepino pode ser irrigada com água salina de até $1,8 \mathrm{dS} \mathrm{m}^{-1}$ durante a sua fase de crescimento inicial.

Palavras-chave: Cucumis sativus L., Irrigação, Salinidade.

\section{INITIAL GROWTH AND TOLERANCE OF UNDER SALT STRESS CUCUMBER CULTIVARS}

\footnotetext{
ABSTRACT

*Autor correspondente

1 Departamento de Ciências Vegetais, UFERSA, Caixa Postal 137, CEP 59625-900, Mossoró (RN); ricardoalbuquerque2016@ hotmail.com; emanuelappaiva@ hotmail.com;

${ }^{2}$ Departamento de Engenharia Agrícola, CTRN/UFCG, Caixa Postal 882, CEP 58.429-900, Campina Grande (PB); vaniesagronomia@hotmail.com.

3 Unidade Acadêmica de Ciências Agrárias, CCTA/UFCG, Caixa Postal 1770, CEP 58840-000, Pombal (PB); fernanda_boka24@hotmail.com; erbiabressiaga@gmail.com; lauter@ccta.ufcg.edu.br.
} 
Cucumber is a vegetable of great economic importance and food, due to its appreciation as a salad component. However, its cultivation in semiarid presents a risk due to salinity problems, necessitating the identification of tolerant cultivars which developed best in environments with salinity problems. Thereby, in order to study the emergence, growth and tolerance of cucumber cultivars to salt stress. The experiment was conducted in a protected environment (greenhouse) in the municipality of Pombal, Paraíba, PB, Brazil. The study was arranged in a factorial $2 \times 5$, a completely randomized design, consisting of two cultivars of cucumber (C1 - Aopdai and C2 - Wisconsin SEM-58) and five levels of irrigation water salinity $\left(0.6\right.$ (control) $, 1,2,1.8,2.4$ and $\left.3.0 \mathrm{dS} \mathrm{m}^{-1}\right)$ with four replications and ten plants per plot. The cucumber plants were conducted for 20 days, in which it evaluated the emergency seedlings early growth, the accumulation of biomass and the tolerances index of cultivars regarding the biomass yield. The salinity of the irrigation water affects the emergence, growth and biomass accumulation of cucumber plants. Cultivar Aopdai has the highest emergence rates, growth and biomass accumulation in relation to cultivate Wisconsin SEM-58. The cucumber crop may be irrigated with saline water to 1.8 $\mathrm{dS} \mathrm{m} \mathrm{m}^{-1}$ during their early growth stage.

Keywords: Cucumis sativus L., Irrigation, Salinity.

\section{INTRODUÇÃO}

O pepino (Cucumis sativus L.) é uma hortaliça de frutos pertencente à família Cucurbitaceae, no Brasil, sua comercialização tem obtido crescimento na importância entre as hortaliças, devido a sua apreciação como componente de saladas (SILVA et al., 2014). Os grupos: Aodai, Caipira e Japonês, são os principais grupos cultivados no Brasil, com destaque para as regiões Sudeste e Nordeste do país, atingindo produtividade média oscilando de 40 a 50 t/ha de frutos (FILGUEIRA, 2008; AGRIANUAL, 2010).

O cultivo do pepino na região nordeste do país apresenta risco, devido a grande parte de essa região apresentar clima semiárido, caracterizado por baixas precipitações pluviométricas, e águas disponíveis para irrigação contendo autos teores de sais (MEDEIROS et al., 2003). Sendo a cultura do pepino considerada moderadamente sensível à salinidade, apresentando salinidade limiar de 2,2 dS $\mathrm{m}^{-1}$ (AYERS; WESTCOT, 1999), que rotineiramente é ultrapassado pelos níveis de salinidade usualmente encontrados na águas disponíveis para irrigação, afetando o crescimento e o rendimento da cultura (MEDEIROS et al., 2009; SANTANA et al., 2010).

No entanto, a tolerância das culturas a salinidade pode ser definida como a capacidade da planta em suportar determinados níveis de sais, que é variável e relação ao genótipo e sua fase de desenvolvimento e a natureza e intensidade do estresse (SÁ et al., 2013; BRITO et al., 2014; OLIVEIRA et al., 2015). Com isso, o estudo de cultivares tolerantes de hortaliças vem se demostrando uma alternativa viável para o convívio com a salinidade em regiões semiáridas, podendo-se citar os estudos de: Medeiros et al. (2007), em cultivares de melão; Martins et al. (2013), em cultivares de melancia e por Oliveira et al. (2014) em cultivares de aboboras e morangas. Todavia, os estudos direcionados ao pepino relacionam apenas um híbrido, que não caracterizam o potencial das cultivares comerciais existentes no mercado (MEDEIROS et al., 2009; SANTANA et al., 2010).

Com isso, objetivou-se avaliar a emergência, o crescimento e a tolerância de cultivares de pepino ao estresse salino.

\section{MATERIAL E MÉTODOS}

$\mathrm{O}$ experimento foi desenvolvido em ambiente protegido (casa de vegetação) do Centro de Ciências e Tecnologia Agroalimentar - CCTA da Universidade Federal de Campina Grande - UFCG, localizado no município de Pombal, Paraíba, PB, nas coordenadas geográficas $6^{\circ} 47^{\prime} 20^{\prime \prime}$ ' de latitude $\mathrm{S}$ e $37^{\circ} 48^{\prime} 01^{\prime \prime}$ de longitude $\mathrm{W}$, a uma altitude de $194 \mathrm{~m}$, no período de agosto a setembro de 2014. 
$\mathrm{O}$ estudo foi arranjado em esquema fatorial 2 x 5 um delineamento experimental inteiramente casualizado, constituído de duas cultivares de pepino (C1 - Aopdai e C2Wisconsin SEM-58) e cinco níveis de salinidade da água de irrigação $(0,6$ (controle; 1,$2 ; 1,8,2,4$ e $3,0 \mathrm{dS} \mathrm{m}^{-1}$ ) sendo três abaixo e dois acima da salinidade limiar da cultura 2,2 $\mathrm{dS} \mathrm{m}^{-1}$ (AYERS; WESTCOT, 1999), com quatro repetições e dez plantas por parcela.

As plantas de pepino foram cultivadas em bandejas de 30 cédulas com capacidade de 0,1 $\mathrm{dm}^{3}$ de substrato, durante os primeiros 20 dias após a semeadura. O substrato para a produção de mudas foi composto por solo (Neossolo Flúvico) (EMBRAPA, 2013) e substrato comercial na proporção $1: 1$, respectivamente (Tabela 1). Para o semeio foram distribuídas cinco cédulas por tratamento, de modo que, cada cédula recebeu duas sementes, totalizando 10 sementes por tratamento, e após a total emergência realizou-se o desbaste deixando-se apenas a planta mais vigorosa por cédula. As sementes, de ambas as cultivares, foram adquiridas em casa comercial apresentando $99 \%$ de pureza e $95 \%$ de germinação.

Tabela 1. Características químicas dos componentes do substrato usado no cultivo do pepino.

\begin{tabular}{ccccccccccccc}
\hline & $\begin{array}{c}\mathrm{CE} \\
\mathrm{dS} \mathrm{m}{ }^{-1}\end{array}$ & $\begin{array}{c}\mathrm{pH} \\
\mathrm{H}_{2} 0\end{array}$ & $\begin{array}{c}\mathrm{P} \\
\mathrm{mg} \mathrm{dm}^{-3}\end{array}$ & $\mathrm{~K}^{+}$ & $\mathrm{Ca}^{+2}$ & $\mathrm{Mg}^{+2}$ & $\mathrm{Na}^{+}$ & $\mathrm{Al}^{3+}$ & $\mathrm{H}^{+}+\mathrm{Al}^{3+}$ & $\mathrm{SB}$ & $\mathrm{T}$ & $\mathrm{MO}$ \\
\hline $\mathrm{A}$ & 0,09 & 8,07 & 3,00 & 0,32 & 6,40 & 3,20 & 0,18 & 0,00 & 0,00 & 10,49 & 10,49 & 16,0 \\
$\mathrm{~B}$ & 1,65 & 5,75 & 86,00 & 1,67 & 11,60 & 28,50 & 17,84 & 0,00 & 11,88 & 59,61 & 71,49 & 570,0 \\
\hline
\end{tabular}

$\mathrm{SB}=$ soma de bases; $\mathrm{CE}=$ condutividade elétrica; $\mathrm{T}=$ capacidade de troca de cátions total; $\mathrm{M} . \mathrm{O}=$ matéria orgânica; $\mathrm{A}=$ Solo; $\mathrm{B}=$ substrato comercial.

As irrigações foram realizadas uma vez ao dia, de modo a deixar o solo com umidade próxima à capacidade de campo, com base no método da lisimétria de drenagem, sendo a lâmina aplicada acrescida de uma fração de lixiviação de $20 \%$. O volume aplicado (Va) por recipiente foi obtido pela diferença entre a lamina anterior (La) aplicada menos a média de drenagem (d), dividido pelo número de recipientes $(\mathrm{n})$, como indicado na equação 1:

$$
V a=\frac{L a-D}{n(1-F L)} \quad \text { Eq. } 1
$$

No preparo da água de irrigação com vários níveis de salinidade, foi considerada a relação entre $\mathrm{CE}_{\mathrm{a}}$ e concentração de sais $\left(10^{*}\right.$ meq $\mathrm{L}^{-1}=1 \mathrm{dS} \mathrm{m} \mathrm{m}^{-1}$ de $\left.\mathrm{CE}_{\mathrm{a}}\right)$ extraída de Rhoades et al. (1992), válida para $\mathrm{CE}_{\mathrm{a}}$ de $0,1 \mathrm{a}$
$5,0 \mathrm{dS} \mathrm{m}^{-1}$ em que se enquadram os níveis testados. Foi utilizada água de abastecimento existente no local $\left(\mathrm{CE}_{\mathrm{a}}=0,3 \mathrm{dS} \mathrm{m}^{-1}\right)$ acrescida de sais $(\mathrm{NaCl})$ conforme necessário (Tabela 2$)$.

$$
\text { Após preparadas, as águas }
$$

salinizadas foram armazenadas em recipientes plásticos de $30 \mathrm{~L}$, um para cada nível de $\mathrm{CE}_{\mathrm{a}}$ estudado, devidamente protegidos, evitando-se a evaporação, a entrada de água de chuva e a contaminação com materiais que pudessem comprometer sua qualidade. Para preparo das águas, com as devidas condutividades elétricas (CE), os sais foram pesados conforme tratamento, adicionando-se águas, até ser atingido o nível desejado de CE, conferindo-se os valores com um condutivímetro portátil, que tem sua condutividade ajustada à temperatura de $25^{\circ} \mathrm{C}$.

\begin{tabular}{|c|c|c|c|c|c|c|c|c|c|c|c|}
\hline \multirow{2}{*}{ Água } & $\begin{array}{c}\mathrm{CE}_{\mathrm{a}} \\
\mathrm{dSm}{ }^{-1}\end{array}$ & $\mathrm{pH}$ & $\mathrm{K}$ & $\begin{array}{c}\mathrm{Ca} \\
\ldots \ldots \ldots \\
\end{array}$ & $\begin{array}{ll}\mathrm{Mg} \\
\ldots \ldots . .\end{array}$ & $\begin{array}{l}\mathrm{Na} \\
\ldots . .(\mathrm{r}\end{array}$ & $\begin{array}{l}\mathrm{SO}_{4}^{-2} \\
\left.\mathrm{l}_{\mathrm{c}} \mathrm{L}^{-1}\right) .\end{array}$ & $\mathrm{CO}_{3}^{-2}$ & $\begin{array}{c}\mathrm{HCO}_{3} \\
\ldots \ldots \ldots .\end{array}$ & $\mathrm{Cl}$ & $\begin{array}{c}\mathrm{RAS}^{1} \\
\left(\mathrm{mmol}_{\mathrm{C}} \mathrm{L}^{-1}\right)^{0,5}\end{array}$ \\
\hline & 0,3 & 7,0 & 0,3 & 0,2 & 0,6 & 1,4 & 0,2 & 0,0 & 0,8 & 1,3 & 2,21 \\
\hline
\end{tabular}

Tabela 2. Análise química da água utilizada no preparo das soluções.

1. RAS= Razão de absorção de sódio. 
Durante a condução do experimento as plantas foram monitoradas em relação à emergência, por meio de contagens do número de plântulas emergidas, ou seja, com os cotilédones acima do nível do solo, as quais foram realizadas diariamente, sem que estas sejam descartadas, obtendo-se, portanto, um valor cumulativo. Dessa maneira, o número de plântulas emergidas referentes a cada contagem foi obtido subtraindo-se do valor lido, com o valor referente à leitura do dia anterior. Dessa forma, com o número de plântulas emergidas referentes a cada leitura foram calculados o tempo médio de emergência (TME) (dias), empregando-se a seguinte fórmula descrita em Schuab et al. (2006):

$$
\mathrm{TME}=\frac{\left(\mathrm{N}_{1} \mathrm{G}_{1}\right)+\left(\mathrm{N}_{2} \mathrm{G}_{2}\right)+\cdots+\left(\mathrm{N}_{\mathrm{n}} \mathrm{G}_{\mathrm{n}}\right)}{\mathrm{G}_{1}+\mathrm{G}_{2}+\cdots+\mathrm{G}_{\mathrm{n}}} \quad \text { Eq. } 2
$$

Onde: TME $=$ Tempo médio de emergência (dias); $\mathrm{G}=$ número de plântulas emergidas observadas em cada contagem; $\mathrm{N}=$ número de dias da semeadura a cada contagem.

Após a estabilização da emergência foi determinada a percentagem de emergência (PE) (\%), obtida pela relação entre o número de plantas emergidas e o número de sementes plantadas.
Para a monitoração dos aspectos morfológicos da cultura foi realizada análise de crescimento das plântulas aos 20 dias após a semeadura, avaliando-se a altura de planta (AP) $(\mathrm{cm})$, medida com uso de uma régua graduada, pela distância entre o solo e o ápice da planta, o diâmetro do caule (DC) foi determinado a um $\mathrm{cm}$ da superfície do solo e o número de folhas (NF), a partir da contagem das folhas maduras. Ao fim das análises de crescimento, as plantas foram coletadas separando-se a parte aérea e raízes e acondicionadas em estufa de circulação de ar à $65^{\circ} \mathrm{C}$, para secagem do material, que após atingir massa constante posteriormente foram pesados em balança analítica determinando-se, com isso, a massa seca da parte aérea (MSPA) (g), a raiz (MSR) (g). De posses desses dados, foi determinada a massa seca total (MST) por meio do somatório da MSPA e da MSR.

Com os dados de produção de matéria seca total foram calculadas as percentagens particionadas entre os órgãos vegetativos e o índice de tolerância à salinidade, comparando-se os dados dos tratamentos salinos com os do controle $\left(\mathrm{CEa}=0,6 \mathrm{dS} \cdot \mathrm{m}^{-1}\right)$, de acordo com a seguinte Eq.:

$$
I T(\%)=\frac{\text { Produçãode MST no tratamento salino }}{\text { Produçãode MST no tratamento controle }} \times 100
$$

\section{Eq.3}

Nos cálculos desses índices utilizaram-se a produção de matéria seca total dos genótipos como parâmetro principal para determinação da tolerância dos materiais ao estresse salino.

Os dados obtidos foram submetidos à análise de variância teste 'F', e nos casos de significância foram realizadas análises de regressão para o fator níveis de salinidade da água de irrigação e teste de média Tukey para o fator cultivares, ambos ao nível de $5 \%$ de probabilidade, com auxilio do software estatístico SISVAR® (FERREIRA, 2011).

\section{RESULTADOS E DISCUSSÃO}

Observou-se influencia significativa da interação salinidade e cultivares de pepino para a variável NF nível de 5\% de probabilidade. Para as variáveis: VE, PE, AP, MSPA, MST e IT averiguaram-se influencia significativas dos fatores isolados. Ressalta-se que para as variáveis DC e MSR observou-se efeito significativo apenas dos níveis de salinidade da água de irrigação, ambos a $1 \%$ de probabilidade. Para relação raiz parte aérea (RRPA) não foi constatado influência dos fatores estudados (Tabela 3). Influência significativas da salinidade sob o crescimento de Cucurbitáceas também foram verificados por Medeiros et al. (2007), em cultivares de melão; Martins et al. (2013), em cultivares de melancia e por Oliveira et al. (2014) em cultivares de 
aboboras e morangas. Esses autores observaram que os níveis mais altos de salinidade estudados afetaram drasticamente o crescimento das cultivares sensíveis, inviabilizado a sua fase crescimento inicial e a produção de mudas das culturas.

O tempo médio de emergência das plântulas de pepino foi influenciada diretamente pelo aumento da salinidade averiguando-se comportamento linear crescente do número de dias exigidos para emergência das plantas, com acréscimos unitários de 0,56 dias em função do aumento da salinidade da água (Figura 1A). Resultados similares também foram encontrados por Soares et al. (2010) trabalhando com sementes de melão crioulo, detectaram que a salinidade afetava o índice de emergência, levando a concluir que conforme aumenta a salinidade diminui o tempo médio de emergência de plântulas possivelmente devido ao efeito osmótico que afetam a embebição e consequentemente a germinação e estabelecimento da plântula (TAIZ; ZAIGER 2013).

Tabela 3. Resumo da análise de variância para as variáveis: Tempo médio de emergência (VE), percentagem de emergência (PE), altura de plantas (AP), número de folhas (NF), diâmetro do caule (DC), massa seca da parte aérea (MSPA), massa seca da raiz (MSR), relação raiz parte aérea (RRPA), massa seca total (MST) e índice de tolerância (IT) de cultivares de pepino sob diferentes salinidade da água de irrigação.

\begin{tabular}{|c|c|c|c|c|c|c|}
\hline \multirow{2}{*}{$\begin{array}{c}\text { Fontes de } \\
\text { variação }\end{array}$} & \multirow{2}{*}{ GL } & \multicolumn{5}{|c|}{ Quadro Médio } \\
\hline & & VE & $\mathrm{PE}$ & AP & $\mathrm{NF}$ & $\mathrm{DC}$ \\
\hline Cultivares & 1 & $7,99^{* *}$ & $2676,42^{* *}$ & $6,76^{* *}$ & $0,40^{\mathrm{ns}}$ & $0,01^{\mathrm{ns}}$ \\
\hline $\mathrm{Sal}$ & 4 & $1,71^{\text {** }}$ & $564,88^{* *}$ & $4,34^{* * *}$ & $3,20^{* *}$ & $0,38^{* *}$ \\
\hline Cultivares x Sal & 4 & $0,49^{\text {ns }}$ & $83,31^{\text {ns }}$ & $0,11^{\mathrm{ns}}$ & $0,45^{*}$ & $0,0071^{\mathrm{ns}}$ \\
\hline Erro & 20 & 0,35 & 111,12 & 0,38 & 0,14 & 0,03 \\
\hline $\mathrm{CV}(\%)$ & & 11,29 & 12,74 & 11,40 & 11,70 & 6,77 \\
\hline Média & & 5,307 & 82,77 & 5,47 & 3,21 & 2,79 \\
\hline \multirow{2}{*}{$\begin{array}{c}\text { Fontes de } \\
\text { variaçãão }\end{array}$} & \multirow{2}{*}{ GL } & \multicolumn{5}{|c|}{ Quadro Médio } \\
\hline & & MSPA & MSR & RRPA & MST & IT \\
\hline Cultivares & 1 & $0,00061^{*}$ & $0,000033^{\text {ns }}$ & $0,0045^{\text {ns }}$ & $0,00093^{*}$ & $175,28^{\text {ns }}$ \\
\hline Sal & 4 & $0,0012^{* *}$ & $0,000382^{* *}$ & $0,017^{\mathrm{ns}}$ & $0,00297^{* *}$ & $2555,10^{* * *}$ \\
\hline Cultivares x Sal & 4 & $0,000029^{\mathrm{ns}}$ & $0,000005^{\mathrm{ns}}$ & $0,0011^{\mathrm{ns}}$ & $0,000042^{\text {ns }}$ & $28,18^{\mathrm{ns}}$ \\
\hline Erro & 20 & 0,000046 & 0,000036 & 0,0092 & 0,000105 & 56,14 \\
\hline CV (\%) & & 11,32 & 28,28 & 27,68 & 12,63 & 9,79 \\
\hline Média & & 0,059 & 0,021 & 0,348 & 0,081 & 76,57 \\
\hline
\end{tabular}

**, $* \mathrm{e}^{\mathrm{ns}}$ significativo a $1 \%$, a $5 \%$ e não significativo respectivamente.

Observou-se comportamento linear decrescente da porcentagem de emergência das plântulas de pepino em função do aumento da salinidade da água de irrigação, obtendo-se reduções de $26 \%$ na emergência das plântulas irrigadas com o maior nível de salinidade $\left(3,0 \mathrm{dS} \mathrm{m}^{-1}\right)$ em relação ao menor nível de salinidade estudado $\left(0,6 \mathrm{dS} \mathrm{m}^{-1}\right)$ (Figura 1C). Esse comportamento pode estar relacionado à redução da capacidade de embebição da semente devido ao aumento do potencial osmótico do substrato, retardando ou inviabilizando a germinação, e consequentemente a emergências das plântulas de pepino, comportamento também verificado nesse trabalho. Os resultados observados corroboram Oliveira et al. (2015) avaliando a emergência e o crescimento inicial de plântulas de beterraba cv. Chata do Egito sob diferentes níveis de salinidade da água de irrigação. Os quais destacam, que o aumento excessivo da salinidade afeta diretamente $\mathrm{o}$ potencial fisiológico da semente, afetando com isso, a percentagem e velocidade de emergência. 
A

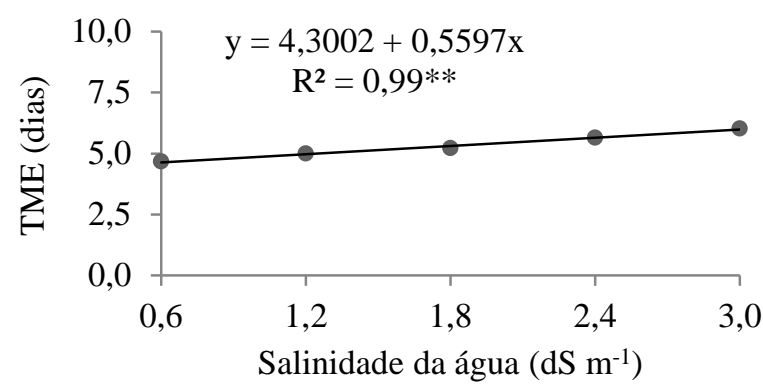

C

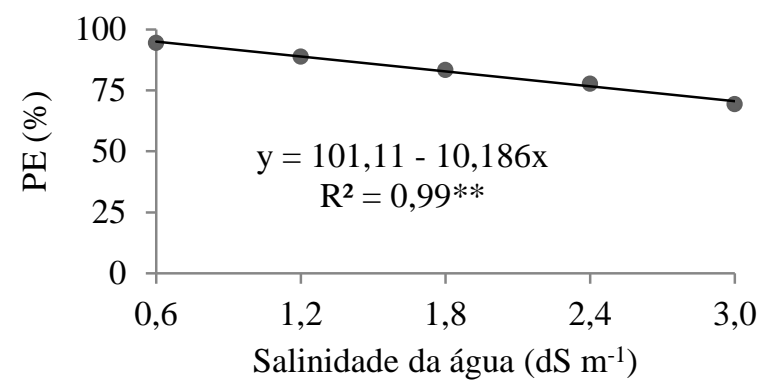

B

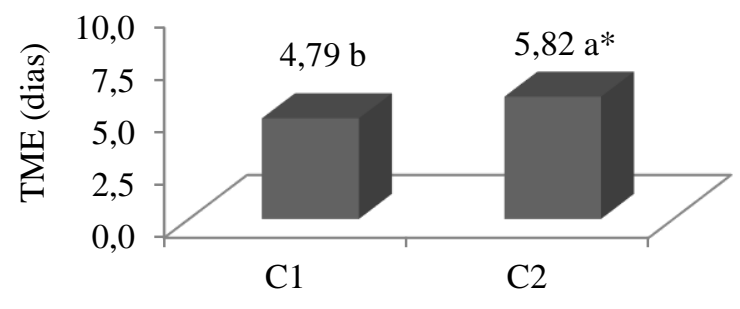

$\mathrm{D}$

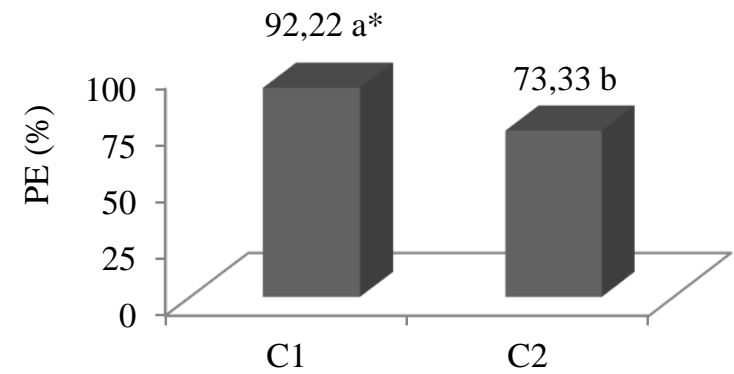

C1

** e * significativo a 1 e $5 \%$ de probabilidade. Letras iguais não diferem pelo teste ' $\mathrm{t}$ ' de Student.

Figura 1. Tempo médio de emergência (TME) (A e B), percentagem de emergência (PE) (C e D) de cultivares de pepino (C1 -Aopdai e C2- Wisconsin SEM-58) sob diferentes níveis de salinidade da água de irrigação.

Verifica-se ainda, que a cultivar Aopdai (4,79 dias) obteve emergência mais rápida em relação a cultivar Wisconsin SEM-58 (5,82 dias), denotando a sua maior eficiência e vigor em ambientes salinos (Figura 1B). Vale salientar, que a cultivar Aopdai sobressaiu em relação cultivar Wisconsin SEM-58, obtendo maiores percentagens de emergência independente dos níveis de salinidade estudados, indicando um maior vigor e tolerância ao estresse salino (Figura 1D). Fato importante, haja vista, que aquisição de sementes é uma das etapas mais encarece da produção de plantas hortícolas no país, desse modo, plantas com capacidade de manter altos índices de germinação em ambientes salinos favorecem obtenção de plantas mais vigorosas, e a redução dos custos com sementes na fase de produção de mudas.

Verificou-se que para cada aumento unitário da salinidade da água reduções de 0,88 $\mathrm{cm}$ na altura das plantas de pepino, o que corresponde a $13,5 \%$ da altura observadas nas plântulas cultivadas sob o tratamento testemunha (Figura 2A). Sendo, o maior crescimento em altura observado na cultivar Aopdai com $16 \%$ a mais em relação à Wisconsin SEM-58, independente dos níveis de salinidade estudados (Figura 2B). Assim como verificado para altura de planta, o diâmetro caulinar das mudas sofreu interferência da salinidade da água da irrigação, proporcionando assim, reduções de 0,24 mm no diâmetro de acordo com o aumento da concentração de sais $\left(\mathrm{dS} \mathrm{m}{ }^{-1}\right)$ na salinidade da água (Figura 2C). 
A

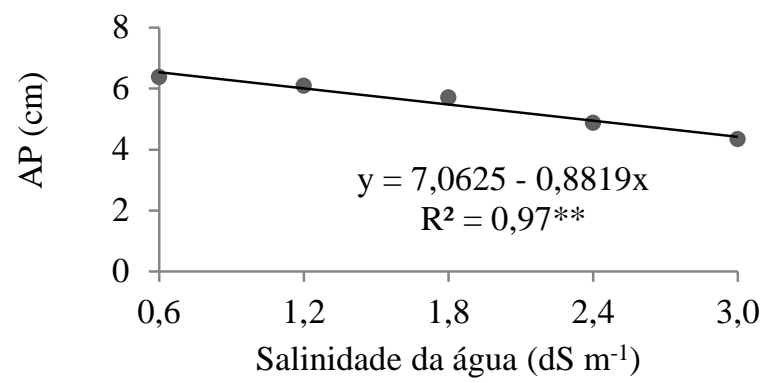

$\mathrm{C}$

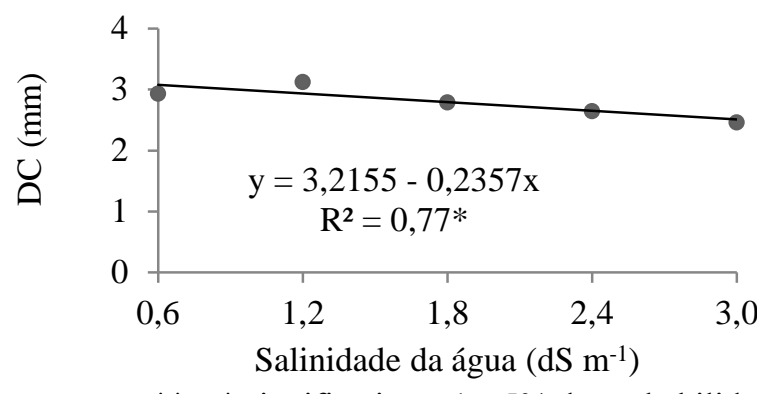

B

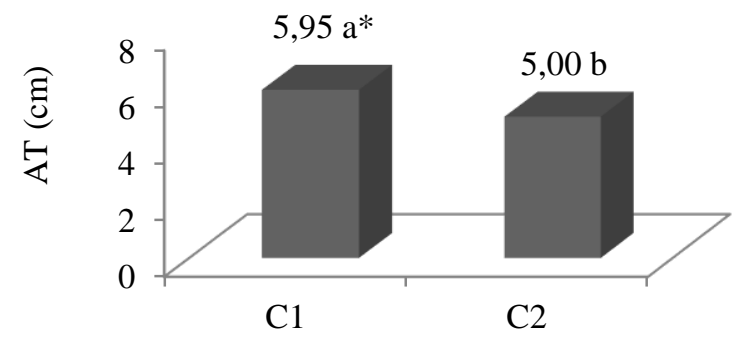

$\mathrm{D}$

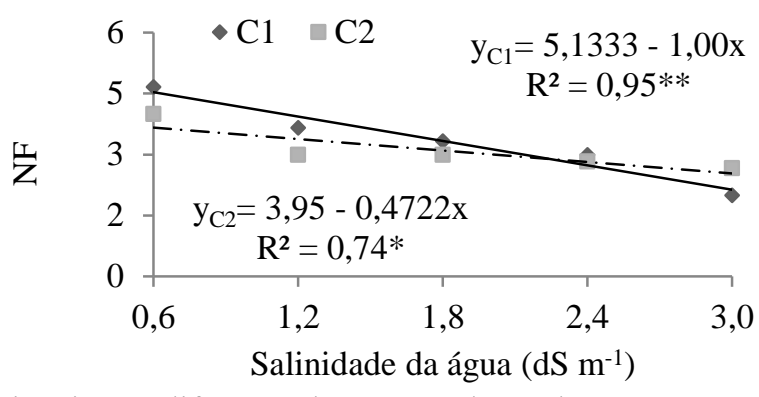

Figura 2. Altura de planta (AP) (A e B), diâmetro do caule (DC) (C) e número de folhas (NF) (D) de cultivares de pepino (C1 -Aopdai e C2- Wisconsin SEM-58) sob diferentes níveis de salinidade da água de irrigação.

O efeito negativo da salinidade sobre o crescimento também foi relatado por Medeiros et al. (2007) e Oliveira et al. (2014), trabalharam com plantas de meloeiro, abóboras e morangas submetidas ao estresse salino, respectivamente. Esse comportamento deve as altas concentrações de sais de sódio interagem negativamente na fisiologia das plantas por promover interações iônicas, osmóticas e nutricionais deletérias às plantas, afetando o seu crescimento e acúmulo de biomassa das plantas (MUNNS; TESTER, 2008; TAIZ; ZEIGER, 2013; SÁ et al., 2013).

Quanto ao número de folhas, observou-se a interação entre salinidade vs. cultivar, verificando-se que a cultivar Aopdai obteve maior número de folha em relação a cultivar Wisconsin SEM-58, quando irrigada até o nível de $1,8 \mathrm{dS} \mathrm{m}^{-1}$, no entanto, esta cultivar obteve as maiores reduções na emissão de folhas em função do aumento da salinidade até o nível de

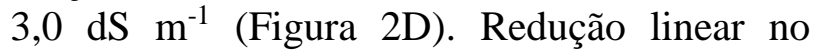
número de folhas em resposta ao aumento da salinidade da água de irrigação tem sido observada nas culturas do meloeiro, melancia e maxixeiro, respectivamente (QUEIROGA et al.,
2006; OLIVEIRA et al., 2012; MARTINS et al. 2013). A redução do número de folhas em detrimento do estresse salino, pode estar relacionado a redução do crescimento vertical caulinar, reduzindo com isso a emissão de gemas foliares, ou até mesmo a morte de gemas em função do excesso de íons tóxicos a planta no meio de cultivo a exemplo do sódio que desencadeia uma serie de desordens fisiológicas, hormonais e nutricionais sob a planta limitando o seu crescimento e desenvolvimento (EPISTEIN; BLOOM, 2006; SÁ et al., 2013; TAIZ; ZAIGER et al., 2013).

O aumento da condutividade elétrica da água reduziu a massa seca total das plantas de pepino, observando-se assim efeito linear decrescente em função do aumento da salinidade da água de irrigação (Figura 3A). A inibição no crescimento e produção de fitomassa pelas plantas em geral, inclusive o pepino, é resposta do desequilíbrio nutricional e toxicidade, que resultam em perdas de respiração, expansão radicular, absorção de água e fixação de $\mathrm{CO}_{2}$ (WILLADINO et al., 2011). Esse comportamento foi semelhante ao observados na massa seca da parte aérea (Figura $3 \mathrm{C}$ ) e das 
raízes de pepino (Figura 3E), verificando-se drásticas reduções no acúmulo de massa seca em função do aumento da salinidade. A redução do acúmulo de fitomassa na parte aérea em função do aumento da salinidade indica ineficiência do processo fotossintético, de

A

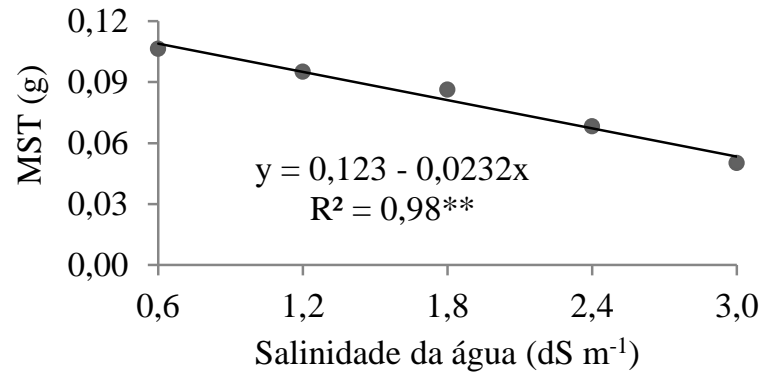

C

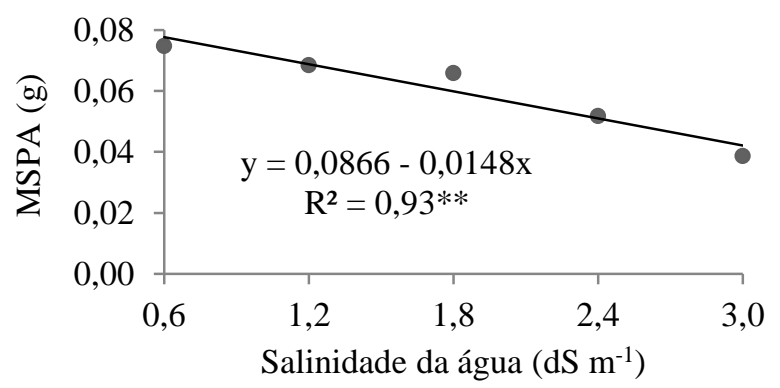

E

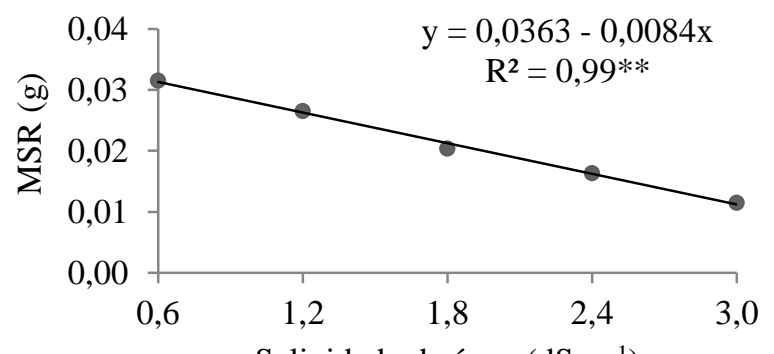

Salinidade da água $\left(\mathrm{dS} \mathrm{m}^{-1}\right)$ modo que os produtos oriundos da fotossíntese não são suficientes para suprir as necessidade dos órgãos das plantas, e ao mesmo tempo promover o crescimento destes (OLIVEIRA et al. 2015).

B

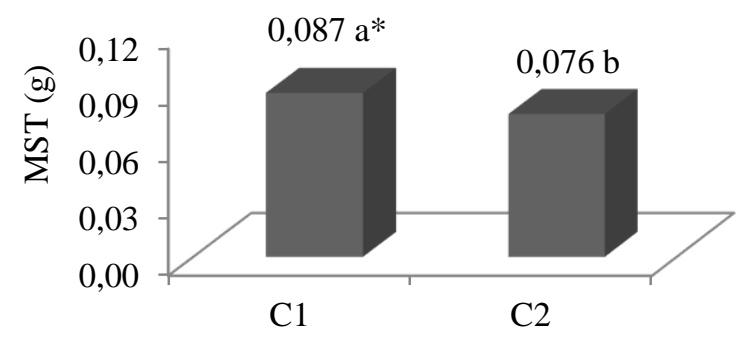

$\mathrm{D}$

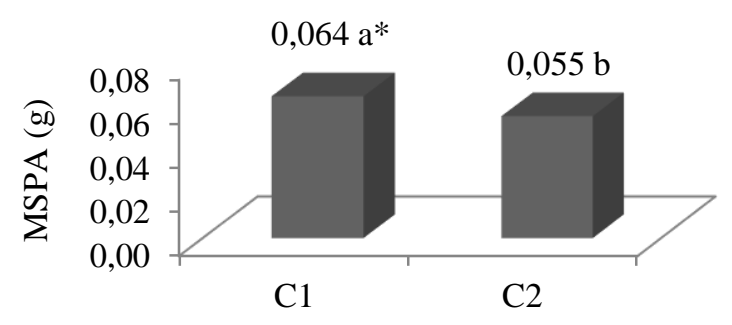

$\mathrm{F}$

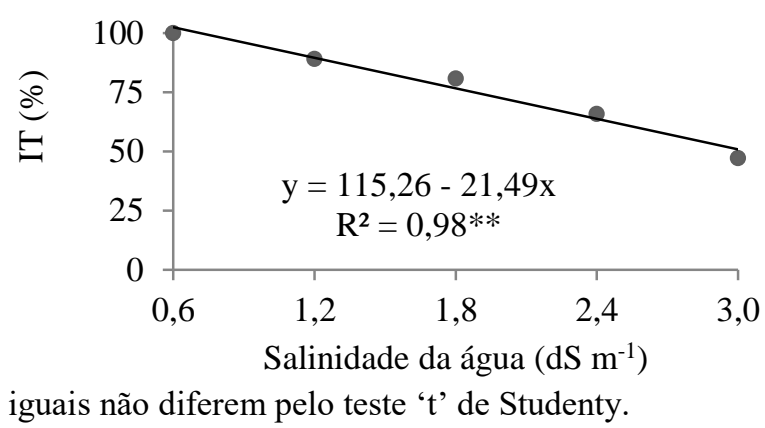

Figura 3. Massa seca total (MST) (A e B), massa seca da parte aérea (MSPA) (C e D), massa seca da raiz (MSR) (E) e índice de tolerância (IT) (F), de cultivares de pepino (C1 -Aopdai e C2-Wisconsin SEM-58) sob diferentes níveis de salinidade da água de irrigação.

Houve diferença significativa entre cultivares quanto ao acúmulo de massa seca, sendo a Aopdai apresentou maior acúmulo de massa seca total e da parte aérea em relação Wisconsin SEM-58 (Figura 3B). Observa-se ainda, que as mesmas não se diferiram em relação ao acúmulo de massa seca radicular, indicando que o maior acúmulo de biomassa ocorrente na cultivar Aopdai, pode estar relacionado ao maior potencial fisiológico dessa cultivar, haja vista que a mesma obteve os melhores índices crescimento em relação a cultivar Wisconsin SEM-58 independente do nível de salinidade estudado (Figuras 2 e 3 ).

As cultivares de pepino estudadas não diferiram estatisticamente quanto ao índice de tolerância, verificando-se apenas efeito significativo nos níveis de salinidade, que reduziu linearmente a tolerância das plantas em função do aumento da salinidade, sendo 
averiguado rendimentos de até $81 \%$ no nível de $1,8 \mathrm{dS} \mathrm{m}^{-1}$ (Figura 2F). Denotando que a fase de crescimento inicial da cultura do pepino é mais sensível em relação às demais fase da cultura, haja vista, que sua salinidade limiar do extrato de saturação média é de 2,2 $\mathrm{dS} \mathrm{m}^{-1}$ (AYERS; WESTCOT, 1999). A irrigação com água de alta salinidade ultrapassou a salinidade limiar levando as plantas a condições.

\section{CONCLUSÕES}

A salinidade da água de irrigação afeta a emergência, o crescimento e o acúmulo de massa seca das plantas de pepino.

A cultivar Aopdai apresenta os maiores índices de emergência, o crescimento e o acúmulo de massa seca em relação a cultivar Wisconsin SEM-58.

A cultura do pepino pode ser irrigada com água salina de até $1,8 \mathrm{dS} \mathrm{m} \mathrm{m}^{-1}$ durante a sua fase de crescimento inicial, com breves perdas no crescimento.

\section{REFERENCIAS}

AGRIANUAL 2010: anuário estatístico da agricultura brasileira. São Paulo: Argos Comunicação, 2009. 520 p.

AYERS, R. S.; WESTCOT, D. W. A qualidade da água na agricultura. 2.ed. Campina Grande: UFPB, 1999. 153p. FAO. Estudos de Irrigação e Drenagem, 29 revisado.

BRITO, M. E. B.; FERNANDES, P. D.; GHEYI, H. R.; MELO, A. S.; SOARES FILHO, W. S.; SANTOS, R. T. Sensibilidade à salinidade de híbridos trifoliados e outros portaenxertos de citros. Revista Caatinga, v. 27, n. 1, p. 17-27, 2014.

EMBRAPA. Centro Nacional e Pesquisa de Solos. Sistema Brasileiro de Classificação de Solos. 3. ed. Brasília, DF: Embrapa Solos 2013. $353 \mathrm{p}$.
Epstein, E.; Bloom, A. J. Nutrição mineral de plantas: Princípios e perspectivas. 2.ed. Londrina: Planta, 2006. 403p.

FERREIRA, D. F. Sisvar: a computerstatisticalanalysis system. Ciência e Agrotecnologia, v. 35, p. 1039-1042, 2011.

FILGUEIRA, F. A. R. Novo manual de olericultura: agrotecnologia moderna na produção e comercialização de hortaliças. 3. ed. Viçosa: UFV, 2008. 421 p.

MARTINS, D. C.; RIBEIRO, M. S. S.;SOUZA NETA, M. L.;SILVA, R. T.;GOMES, L. P.;GUEDES, R. A. A.;OLIVEIRA, F.A. Tolerância de cultivares da melancia à salinidade da água de irrigação. Agropecuária Científica no Semiárido, v. 8, n. 3, p. 62-68, 2013.

MEDEIROS, J. F. DE; LISBOA, R. DE A.; OLIVEIRA, M. DE; SILVA JÚNIOR, M. J. DA; ALVES, L. P. Caracterização das águas subterrâneas usadas para irrigação na área produtora de melão da Chapada do Apodi. Revista Brasileira Engenharia Agrícola e Ambiental, v. 7, n. 3, p. 469-472, 2003.

MEDEIROS, J. F.; SILVA, M. C.. C.; SARMENTO, D. H. A.; BARROS, A. D.Crescimento do meloeiro cultivado sob diferentes níveis de salinidade, com e sem cobertura do solo. Revista Brasileira Engenharia Agrícola Ambiental, v. 11, n. 3, p. 248-255, 2007.

MEDEIROS, P. R. F.; DUARTE, S. N.; DIAS, C. T. S. Tolerância da cultura do pepino à salinidade em ambiente protegido. Revista Brasileira de Engenharia Agrícola e Ambiental, v. 13, n. 4, p. 406-410, 2009.

MUNNS, R.; TESTER, M. Mechanisms of salinity tolerance. Annual Review of Plant Biology, v. 59, n. 6, p. 651-681, 2008. 
OLIVEIRA, F. A.; SÁ, F. V. S.; PAIVA, E. P.; ARAÚJO, E. B. G.; SOUTO, L. S.; ANDRADE, R. A.; SILVA, M. K. N. Emergência e crescimento inicial de plântulas de beterraba cv. Chata do Egito sob estresse salino. Agropecuária Científica no Semiárido, v. 11, n. 1, p. 01-06, 2015.

OLIVEIRA, F.A.; MARTINS, D. C.;OLIVEIRA, M. K. T.; SOUZA NETA, M. L.; RIBEIRO, M. S. S.; SILVA, R. T. Desenvolvimento inicial de cultivares de abóboras e morangas submetidas ao estresse salino.Agro@mbiente On-line, v. 8, n. 2, p. 222-229, 2014.

OLIVEIRA, F. A.; OLIVEIRA, M. K. T.; LIMA, L. A.; BEZERRA, F. M. S.; GONÇALVES, A. L. Desenvolvimento inicial do maxixeiro irrigado com águas de diferentes salinidades. Agropecuária Científica no Semiárido, v. 8, n. 2, p. 22-28, 2012.

QUEIROGA, R. C. F.; ANDRADE NETO, R. C.; NUNES, G. H. S.; MEDEIROS, J. F.; ARAÚJO, W. B. M. Germinação e crescimento inicial de híbridos de meloeiro em função da salinidade. Horticultura Brasileira, v. 24, n. 3, p. 315-319, 2006.

RHOADES, J.D.; LOVEDAY, J. Salinity in irrigated agriculture.In: STEWART, D. R.; NIELSEN, D. R. (ed.) Irrigation of agricultural crops. Madison: ASA, CSSA, SSSA, 1990. p.1089-1142. (Agronomy, 30).

SÁ, F. V. S.; BRITO, M. E. B.; MELO, A. S.; ANTÔNIO NETO, P.; FERNANDES, P. D.; FERREIRA, I. B. Produção de mudas de mamoeiro irrigadas com água salina. Revista
Brasileira Engenharia Agrícola e Ambiental, v. 17, n. 10, p. 1047-1054, 2013.

SANTANA, M. J.; CARVALHO, J. A.; MIGUEL, D. S. Respostas de plantas de pepino à salinidade da água de irrigação. Global

Science and Technology, v. 3, n. 3, p.94-102, 2010.

SCHUAB, S. R. P.; BRACCINI, A. L.; FRANÇA NETO, J. B.; SCAPIM, C. A.; MESCHEDE, D. K. Potencial fisiológico de sementes de soja e sua relação com a emergência das plântulas em campo. Acta ScientiarumAgronomy, v. 28, n. 4, p. 553-561, 2006.

SILVA, E. F.;SOUZA, E. G. F.; SANTOS, M. G.; ALVES, M. J. G.;BARROS JÚNIOR, A. P.;SILVEIRA, L. M.; SOUSA, T. P. Qualidade de mudas de pepino produzidas em substratos à base de esterco ovino. Agropecuária Científica no Semiárido, v. 10, n. 3, p. 93-99, 2014.

SOARES, A. N. R.; RIBEIRO, M. C. C.; BENEDITO, C. P.; OLIVEIRA, F. N.; GUIMARÃES, L. M. S. Crescimento inicial de plântulas de acesso de melão (Cucumis melo L.) crioulo submetido ao estresse salino. Revista Verde de Agroecologia e Desenvolvimento Sustentável, v. 5, n. 3, p. 224-230, 2010.

TAIZ, L.; ZEIGER, E. Fisiologia vegetal. Porto Alegre: Artmed, 5.ed. 2013. 918p.

WILLADINO, L.; GOMES, E. W. F.; SILVA, E. F. F.; MARTINS, L. S. S.; CAMARA, T. R. Efeito do estresse salino em genótipos tetraplóides de bananeira. Revista Brasileira de Engenharia Agrícola e Ambiental, v. 15, n. 1, p. 53-59, 2011. 